\title{
RIBOFLAVINA: UMA VITAMINA MULTIFUNCIONAL
}

Ana Carolina Santos de Souza, Carmen Veríssima Ferreira, Marilena Bezerra Jucá e Hiroshi Aoyama*

Departamento de Bioquímica, Instituto de Biologia, Universidade Estadual de Campinas, CP 6109, 13083-970 Campinas - SP Alexandre D. Martins Cavagis e Maikel P. Peppelenbosch

Department of Cell Biology, University of Groningen, Antonius Deusinglaan 1, NL-9713 AV, Groningen, The Netherlands

Recebido em 17/8/04; aceito em 5/11/04; publicado na web em 13/4/05

\begin{abstract}
RIBOFLAVIN: A MULTIFUNCTIONAL VITAMIN. Riboflavin, a component of the $\mathrm{B}_{2}$ vitaminic complex, plays important roles in biochemistry, especially in redox reactions, due to the ability to participate in both one- and two-electron transfers as well as acting as a photosensitizer. Accordingly, low intakes of this vitamin have been associated with different diseases, including cancer and cardiovascular diseases. Riboflavin is thought to contribute to oxidative stress through its capacity to produce superoxide but, interestingly, it can also promote the reduction of hydroperoxides. This peculiar and multifunctional behavior allows riboflavin to take part in various biochemical pathways as a nucleophile and an electrophile, turning it into a versatile and important biological compound.
\end{abstract}

Keywords: riboflavin; electron transfer; oxidative stress.

\section{INTRODUÇÃO}

A riboflavina foi isolada (apesar de não purificada) pela primeira vez em 1879 pelo químico inglês A. Wynter Blyth. Em seus estudos relacionados à composição do leite de vaca ele relatara a identificação de um pigmento amarelo brilhante que chamou de "lactocromo" e que hoje nós conhecemos como sendo a riboflavina. Depois desse anúncio, quase cinquienta anos se passaram até que algum avanço significativo ocorresse com o recém descoberto pigmento amarelo-laranja. Então, ao final dos anos 20 e início da década de 30 do século XX, uma grande evolução científica aconteceu e pigmentos amarelos semelhantes com um brilho esverdeado fluorescente foram isolados de uma ampla variedade de fontes ${ }^{1}$. O interesse por eles tornou-se ainda maior quando o tal pigmento amarelo foi reconhecido como sendo um constituinte da vitamina do complexo B, sendo a purificação da própria vitamina amplamente facilitada uma vez que se percebeu que o potencial vitamínico estava intimamente correlacionado à fluorescência da riboflavina. Alguns dos principais químicos da época como Richard Kuhn, em Heidelberg, e Paul Karrer, em Zurich, entraram em uma corrida acirrada para determinar a estrutura, bem como para prová-la através de síntese química, sendo que ambos obtiveram sucesso neste intento quase que concomitantemente. Vários nomes foram propostos para o então caracterizado composto, tais como lactoflavina e ovoflavina a fim de estabelecer correlação com a fonte através da qual o composto havia sido isolado. Mas o prefixo ribo foi consagrado no nome pelo qual conhecemos o composto atualmente, por causa da cadeia ribitil e da cor amarela característica proveniente do sistema $\pi$ conjugado nos anéis isoaloxazina ${ }^{1-3}$.

\section{RIBOFLAVINA E SUAS FUNÇÕES BIOLÓGICAS}

A riboflavina, 7,8-dimetil-10-ribitil-isoaloxazina, é uma vitamina hidrossolúvel pertencente ao complexo vitamínico $\mathrm{B}_{2}$, apresenta coloração amarela e é fluorescente. Além do leite que, como

*e-mail: aoyama@unicamp.br mencionado, foi uma das primeiras fontes de obtenção, a riboflavina é encontrada também em carne, peixe e, principalmente, em vegetais de cor verde-escura ${ }^{4}$. A riboflavina proveniente da dieta encontra-se na forma das coenzimas flavina adenina dinucleotídeo (FAD) e flavina mononucleotídeo (FMN) ligadas a proteínas; no entanto, quando o bolo alimentar chega ao estômago, o meio ácido propicia a liberação das coenzimas. As coenzimas livres sofrerão a ação das pirofosfatases e fosfatases, presentes no intestino delgado, levando à liberação da riboflavina. Observou-se em nosso laboratório que a riboflavina é um importante produto das reações catalisadas pelas fosfatases ácidas (proteína tirosina fosfatases) de baixa massa molecular relativa, purificadas de rim $^{5}$ e pulmão ${ }^{6}$ bovinos, uma vez que a FMN é um potencial substrato fisiológico destas enzimas. A riboflavina liberada pode ser absorvida por transporte ativo ou facilitado ${ }^{6-8}$.

A riboflavina é de fundamental importância em organismos aeróbios, sendo precursora de importantes coenzimas participantes da cadeia transportadora de elétrons como a FAD e FMN ${ }^{4,7,8}$. Também origina muitas das flavinas que se encontram ligadas a diversas enzimas, as quais atuam na catálise de um grande número de importantes reações como, por ex., as relacionadas ao reparo do DNA. A fórmula estrutural da riboflavina é mostrada na Figura 1.

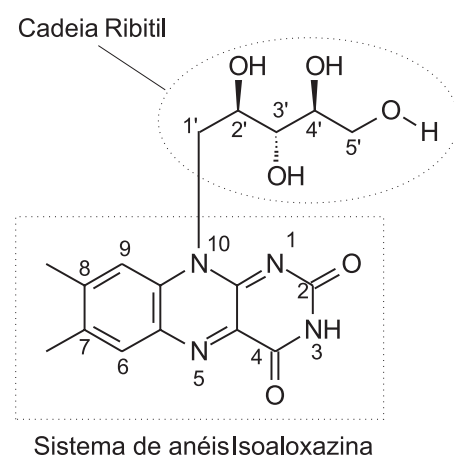

Figura 1. Estrutura da riboflavina $(R F)$. Em destaque, a cadeia ribitil e o sistema de anéis isoaloxazina, que apresenta o sistema $\pi$ conjugado 
O metabolismo de lipídios necessita de derivados da riboflavina, assim como a degradação de drogas e outros compostos químicos exógenos (xenobióticos) via sistema de hidroxilação microssomal. Cofatores de riboflavina são requeridos para o metabolismo do ácido fólico, piridoxina e niacina, além de serem utilizados por enzimas de eritrócitos, como a glutationa redutase que é uma enzima importante pertencente ao sistema de proteção contra as espécies reativas de oxigênio (ROS) geradas nessas células ${ }^{9}$.

Curiosamente, a riboflavina pode tanto contribuir quanto inibir o estresse oxidativo através da sua dupla habilidade de produzir superóxido e, ao mesmo tempo, poder estar envolvida na redução de hidroperóxidos ${ }^{1}$.

Estudos recentes têm correlacionado a riboflavina ao mecanismo de transdução de sinais de células apoptóticas, bem como à regulação do relógio biológico ${ }^{1,10}$.

\section{Conseqüiências da deficiência alimentar}

Atualmente, a dose recomendada de ingestão de riboflavina varia desde $0,4 \mathrm{mg}$ (na infância) a $1,3 \mathrm{mg} /$ dia para adultos sendo que, para mulheres grávidas, recomenda-se uma dose suplementar de $0,3 \mathrm{mg} /$ dia durante a gestação e $0,5 \mathrm{mg} /$ dia durante o período de lactação, já que estudos mostram que durante o terceiro trimestre de gestação há uma queda progressiva nos níveis de riboflavina ${ }^{11,12}$.

Como participa de diversas reações de óxido-redução importantes no metabolismo através dos cofatores FMN e FAD, os quais atuam como carregadores de elétrons, dietas inadequadas de riboflavina poderiam levar a distúrbios no metabolismo intermediário. Em ratos, a deficiência em riboflavina foi associada a uma redução tecido-específica na atividade da succinato oxidorredutase (succinato desidrogenase), efeito este que pode ter implicações na produção de energia através da fosforilação oxidativa. Além disto, a $\beta$-oxidação de ácidos graxos também é dependente de flavinas como aceptores de elétrons ${ }^{13}$.

Em animais, estudos demonstraram que a deficiência de riboflavina está relacionada a desenvolvimentos anormais no feto e, em humanos, vários estudos correlacionam a deficiência de riboflavina com quadros hematológicos, principalmente com aqueles relacionados ao sistema hematopoiético. Atualmente, a influência hematológica da deficiência de riboflavina tem sido associada a sua interferência no metabolismo do ferro, já que a mobilização de ferro a partir da proteína intracelular ferritina é um processo redutivo e flavinas reduzidas podem agir reduzindo o ferro da ferritina e, desta maneira, mobilizá-lo em vários tecidos em concentrações fisiologicamente relevantes. Sintomas de neurodegeneração e neuropatia têm sido documentados em vários estudos de dietas deficientes em riboflavina em diferentes espécies, apesar de haver pouca informação com relação à relevância desses resultados em humanos, mas sabe-se que a riboflavina apresenta uma função no metabolismo da tiroxina e sua carência poderia contribuir com a patofisiologia de algumas doenças mentais ${ }^{14-16}$.

Pesquisas na área de saúde pública relatam a importância da riboflavina como fator de proteção contra doenças cardiovasculares e processos tumorais. Trabalhos publicados durante as décadas de 70 e 80 indicaram que ela poderia apresentar efeitos protetores contra danos teciduais gerados por oxidação. Devido a sua não toxicidade, a riboflavina é um forte candidato como agente redutor do ferro presente no grupo heme de proteínas, atuando como protetor de danos oxidativos em determinados tecidos. No entanto, o potencial terapêutico desta vitamina neste contexto deve ainda ser amplamente investigado, já que a maioria dos estudos até o presente momento foi realizada em modelos animais ${ }^{6}$.

Com relação à visão, sabe-se que a riboflavina é um compo- nente normal das lentes do olho humano e que apresenta uma atividade fotossensibilizadora muito forte quando exposta à luz. Desta forma, radiações com comprimentos de onda abaixo de $400 \mathrm{~nm}$ levariam a uma excitação luminosa que acarretaria, nessas circunstâncias, danos à visão. Vascularização e opacidade na córnea e até mesmo cataratas têm sido relatadas em animais alimentados com dietas pobres em riboflavina. Acredita-se que fotorreceptores dependentes de riboflavina (criptocromos) desempenham uma função importante na adaptação ao escuro e, portanto, a dieta de riboflavina poderia influenciar na adaptação ao escuro através desses fotorreceptores por interação com a vitamina A ou de forma independente $\mathrm{e}^{17,18}$.

Finalmente, a deficiência de riboflavina pode interferir no metabolismo de outros nutrientes, principalmente no metabolismo de outras vitaminas $\mathrm{B}$, tais como folato, cianocobalamina (vitamina $\mathrm{B}_{12}$ ) e piridoxina (vitamina $\left.\mathrm{B}_{6}\right)^{13}$.

\section{RIBOFLAVINA E CÂNCER}

A deficiência de riboflavina tem sido correlacionada como um fator de risco para o câncer, embora este fato ainda não esteja satisfatoriamente estabelecido em humanos, sendo que a influência de dietas deficientes em riboflavina na gênese e progressão do câncer tem sido assunto controverso no meio científico onde existem relatos provando, tanto sua ação estimulatória em certos casos, quanto inibitória em outros. Em geral, a deficiência de riboflavina parece estar relacionada à diminuição do desenvolvimento de tumores espontâneos em animais experimentais mas também, paradoxalmente, ao aumento da carcinogênese provocada por certos agentes ${ }^{6}$.

A correlação entre riboflavina e câncer é bastante complexa e pode ser exemplificada nos inúmeros efeitos desta vitamina no metabolismo de drogas. Por ser precursora de flavocoenzimas do sistema microssomal de hidroxilação de drogas, a carência de riboflavina pode retardar a inativação de carcinógenos e, portanto, aumentar sua distribuição aos tecidos susceptíveis. Por outro lado, se a droga tiver menor atividade carcinogênica que seus metabólitos, a deficiência de riboflavina, possivelmente, terá efeito inibitório sobre a carcinogênese. Deve-se lembrar também que o mesmo raciocínio pode ser aplicado em relação aos quimioterápicos em situações nas quais estes podem, não somente ter seu metabolismo afetado pela disponibilidade de cofatores derivados de riboflavina, como também a sua própria disponibilidade e captação celular afetadas, visto que a riboflavina pode complexar-se com certas substâncias e, também, agir como fator regulatório de sua entrada na célula. Drogas antifolato também podem ter efeito influenciado pela disponibilidade de riboflavina, uma vez que cofatores de flavina estão relacionados ao metabolismo do ácido fólico. Tem sido difícil, contudo, obter evidências que suportem ou refutem essas hipóteses e as pesquisas agora mudam seu foco para a obtenção de dados sobre a real disponibilidade de riboflavina nas células neoplásicas. Células neoplásicas parecem perder certos mecanismos que regulam o metabolismo de riboflavina em tecidos normais e caracterizam-se por resistir à deficiência de riboflavina, o que leva à manutenção de altas concentrações de FAD, através de mecanismos ainda não determinados ${ }^{9,19,20}$.

Durante a década de 1990, uma nova abordagem ao tratamento do câncer foi estudada e, mais uma vez, a riboflavina assumiu um papel de destaque devido a sua característica peculiar de composto fotossensível. Além disso, demonstrou-se que a riboflavina pode apresentar importante função no transporte e liberação controlada de drogas. Este novo aspecto da utilização da riboflavina veio ampliar e consolidar, de maneira significativa, a importância biológica e fisiológica deste composto ${ }^{21-24}$. 


\section{ALGUMAS PROPRIEDADES QUÍMICAS FUNDAMENTAIS DA RIBOFLAVINA}

A riboflavina, bem como as flavinas em geral, apresenta uma característica muito importante para o seu papel biológico que é a capacidade de participar de reações químicas com transferência tanto de dois como também de um elétron, o que implica, neste último caso, a existência de estados de semiquinona ${ }^{1}$.

Em soluções aquosas e na ausência de qualquer tipo de enzima, ocorre um equilíbrio entre a forma oxidada e a forma reduzida da riboflavina (auto-redox) sendo que, neste processo, uma certa quantidade de radical é formada:

$$
\begin{aligned}
\mathrm{RF} & \rightleftharpoons \mathrm{RF}_{\mathrm{ox}}^{+2}+2 \mathrm{e}^{-} \\
\mathrm{RF}+2 \mathrm{H}^{+}+2 \mathrm{e}^{-} & \rightleftharpoons \mathrm{RF}_{\text {red }} \mathrm{H}_{2} \\
2 \mathrm{RF}+2 \mathrm{H}^{+} & \rightleftharpoons \mathrm{RF}_{\mathrm{red}} \mathrm{H}_{2}+\mathrm{RF}_{\mathrm{ox}}^{+2} \\
\mathrm{RF}_{\mathrm{ox}}^{+2}+\mathrm{RF}_{\mathrm{red}} \mathrm{H}_{2} & \rightleftharpoons 2 \mathrm{RFH}^{+\cdot} \\
\mathrm{RFH}^{+\cdot} & \rightleftharpoons \mathrm{RF}^{\cdot}+\mathrm{H}^{+}
\end{aligned}
$$

Esquema 1. Equilíbrios químicos da riboflavina semiquinona. $R F=$ riboflavina; ox $=$ oxidada; red $=$ reduzida

Para maior clareza, apresentamos as semi-reações de oxidação (1) e redução (2) da riboflavina, sendo que a Equação 3 corresponde ao processo global. Os equilíbrios 4 e 5 , em soluções aquosas de riboflavina livre da presença de qualquer enzima, são quase que totalmente deslocados para a esquerda. Para se ter uma referência, partindo de uma mistura equimolar de riboflavina oxidada e reduzida, em pH 7,0, apenas 5\% de radical é estabilizado. Contudo, é importante ressaltar que a presença de enzimas torna possível uma ampla variedade de estados de oxidação para a riboflavina, uma vez que as energias de ativação de diversas reações redox envolvendo a riboflavina são significativamente reduzidas em sistemas enzimáticos. Essa versatilidade de estados de oxidação permite monitorar eventos que ocorrem em catálise utilizando a riboflavina como um marcador, já que suas reações sempre são caracterizadas por semi-reações, que podem ser acompanhadas separadamente.

$\mathrm{Na}$ maior parte dos casos em que a riboflavina é reduzida, o processo pode ocorrer de duas maneiras distintas. A primeira seria através da transferência de dois elétrons por um substrato $\left(\mathrm{S}_{1}\right)$ que é então desidrogenado, gerando uma flavina reduzida, a qual pode ser subsequientemente reoxidada, através de desidrogenação, por outro substrato $\left(\mathrm{S}_{2}\right)$, conforme ilustrado no Esquema 2.

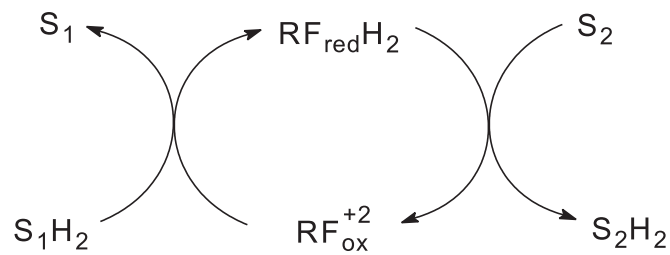

Esquema 2. Semi-reações da riboflavina oxidada e reduzida. $R F=$ riboflavina; red = reduzida; ox = oxidada

A segunda maneira é através de transferência de um único elétron, gerando um intermediário semiquinona. Em alguns casos, o oxigênio molecular é o substrato fisiológico mas, devido à reatividade inespecífica do $\mathrm{O}_{2}$ com flavinas em geral, o estudo de algumas reações deve ser realizado em condições anaeróbicas ${ }^{1}$.
O Esquema 3 mostra reações químicas que podem ocorrer entre riboflavina reduzida e oxigênio:

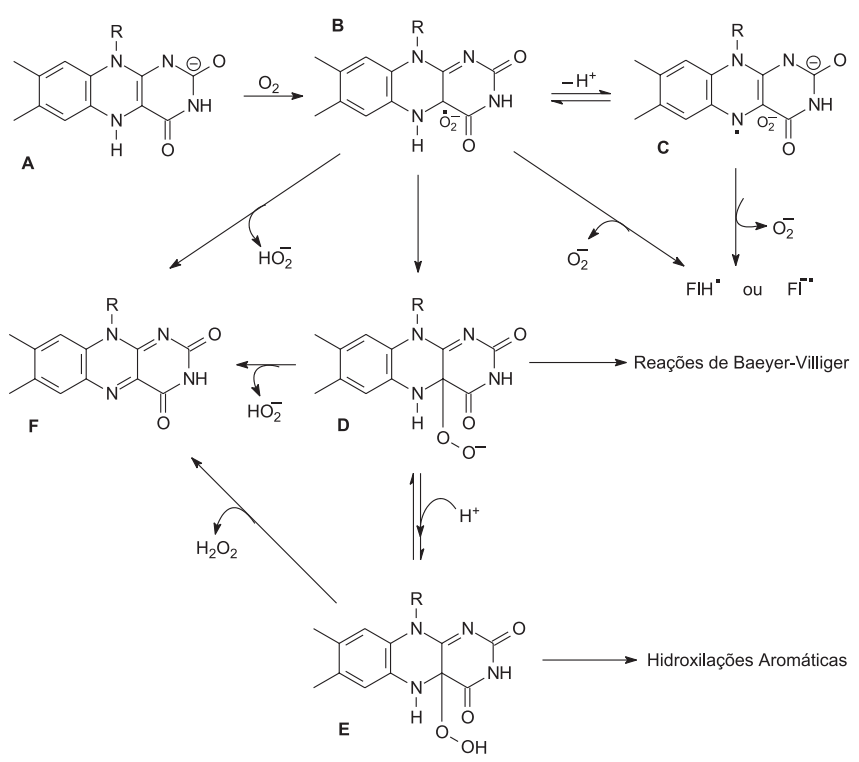

Esquema 3. Reações entre riboflavina reduzida e oxigênio. $R=$ cadeia ribitil

A reação inicial é uma redução de $\mathrm{O}_{2}$ que se dá através da transferência de um único elétron da flavina reduzida (A), gerando um par radicalar formado pela flavina neutra e ânion superóxido (B). $\mathrm{O}$ par radicalar gerado pode, então, seguir várias rotas alternativas como, por ex., levar à formação de uma peroxirriboflavina (D) que é um nucleófilo. Este intermediário pode, por sua vez, ser protonado, gerando um hidroperóxido de características eletrofílicas (E). Além disso, as espécies peroxiconjugadas de riboflavina podem eliminar peróxido de hidrogênio e gerar a riboflavina oxidada $(\mathrm{F})$ ou participar de processos oxidativos, como hidroxilações aromáticas ou reações de Baeyer-Villiger que são oxidações de substratos que possuem grupamentos cetônicos e aldeídos para, respectivamente, ésteres e ácidos carboxílicos. Uma outra possibilidade é a dissociação do par radicalar (B) gerando o radical de riboflavina e o radical superóxido, o qual pode reagir com peróxido para formar radical hidroxil ou com óxido nítrico para formar peroxinitrito. Acreditase que o radical hidroxil seja um dos principais responsáveis por estresse oxidativo e danos teciduais, em grande parte através da reação com lipídios que levam à produção de hidroperoxilipídios. Além disso, trabalhos recentes têm sugerido que o peroxinitrito é um agente importante no processo de apoptose $e^{1,25}$.

\section{Riboflavina: um fotossensibilizador biológico eficiente}

Como já comentado, a riboflavina desempenha um importante papel biológico como sensibilizador fotoquímico. Apresenta, como característica, sensibilidade à radiação UV e visível ${ }^{26,27}$ sendo que, ao absorver luz, alcança o estado triplete excitado que pode tanto interagir com o oxigênio molecular gerando oxigênio singlete (chamado de mecanismo tipo II) ou agir diretamente sobre um substrato levando à fotoxidação deste e à conseqüiente geração de radicais intermediários (mecanismo tipo I), além de espécies reativas de oxigênio, tais como ânion superóxido, radical hidroxil e peróxido de hidrogênio ${ }^{20,28}$. Essa capacidade pode ser útil ao organismo como no caso de enzimas que necessitam de luz visível para o desempenho de suas atividades catalíticas, tais como enzimas participantes do processo de fotossíntese e enzimas de reparo do DNA, DNA 
liases, cujos grupos prostéticos atuam como substratos para o triplete excitado de riboflavina ${ }^{29}$.

A capacidade fotossensibilizadora da riboflavina em sistemas biológicos está relacionada ao alto potencial redox de sua forma triplete ativada. Embora o potencial redox da riboflavina seja $-0,3 \mathrm{~V}$, em pH $7,0^{30}$, sua irradiação e ativação ao estado triplete eleva o potencial redox a $1,7 \mathrm{~V}$ que é bem maior que o potencial redox de importantes biomoléculas como aminoácidos, proteínas, lipídios e ácidos nucléicos que, desta forma, podem sofrer fotodegradação em presença de riboflavina ${ }^{31,32}$. Desta maneira, após a excitação, a transferência de elétrons dos aminoácidos mencionados para formar os respectivos radicais e, conseqüentemente, gerar a riboflavina reduzida acaba sendo termodinamicamente favorecida.

A riboflavina irradiada reage com os aminoácidos triptofano $(\mathrm{TrpH})$, tirosina $(\mathrm{TyrOH}) \mathrm{e}$, em menor extensão, com fenilalanina (PheH) [neste texto, a fim de tornar mais claras as indicações em reações químicas, utilizaremos uma abreviatura para os aminoácidos diferente do padrão internacional de uma ou três letras]. Como resultado da fotoxidação dos aminoácidos mencionados, formamse espécies reativas de oxigênio e outros fotoprodutos tóxicos para as células. Nas proteínas, resíduos de triptofano $(\operatorname{TrpH})$ e tirosina (TyrOH) apresentam potenciais redox de 1,5 e $0,93 \mathrm{~V}$, respectivamente, que os tornam substratos susceptíveis às reações de fotoxidação em presença de riboflavina irradiada ${ }^{33,34}$. Durante essas reações, além da formação de fotoprodutos, como mencionado, também pode haver formação de fotoadutos entre a flavina excitada e seu substrato, como no caso da reação entre riboflavina e $\mathrm{TrpH}$, na qual se observa o aparecimento de fotoadutos indol-flavina e indol-indol, entre outros ${ }^{35}$.

O Esquema 4 mostra possíveis reações importantes na fotossensibilização de triptofano e tirosina pela riboflavina:
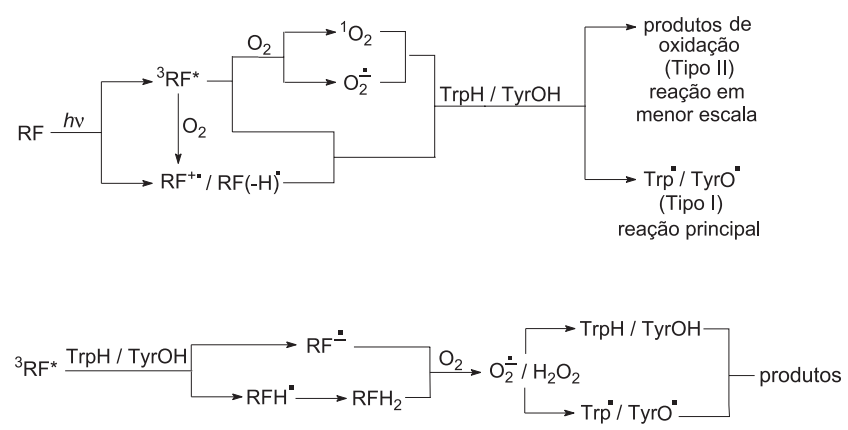

Esquema 4. Possíveis interações importantes para a fotossensibilização de triptofano e tirosina pela riboflavina atuando como fotossensibilizador

A presença de $\operatorname{TrpH}$ e riboflavina tem sido correlacionada a disfunções hepáticas produzidas por nutrição parenteral ${ }^{36}$ e os fotoprodutos da reação têm mostrado exercer efeitos letais em culturas de células animais ${ }^{35,37}$.

Vários estudos têm revelado que a irradiação de células tumorais com luz visível em presença de riboflavina induz a morte celular. Quando células F9 de teratocarcinoma e NSO/2 murinas foram irradiadas em meio de cultura enriquecido com TrpH e riboflavina, alterações morfológicas similares às descritas para células apoptóticas foram observadas. O efeito citotóxico foi atribuído à formação de espécies reativas de oxigênio tais como ânion superóxido e oxigênio singlete, gerados através de um mecanismo relativamente complexo (Esquema 5), misto dos mecanismos tipo I e tipo II $^{17,22}$. Além da produção de ROS, também constatou-se a formação de outros fotoprodutos citotóxicos originados de reações en- volvendo o radical ânion de riboflavina e radical cátion indol do TrpH. Tais fotoprodutos constituem-se, basicamente, de formas agregadas de riboflavina, produtos indólicos associadas a flavinas, produtos indólicos com peso molecular maior que o do $\operatorname{TrpH}$, bem como outros produtos da fotodecomposição deste aminoácido ${ }^{28}$.

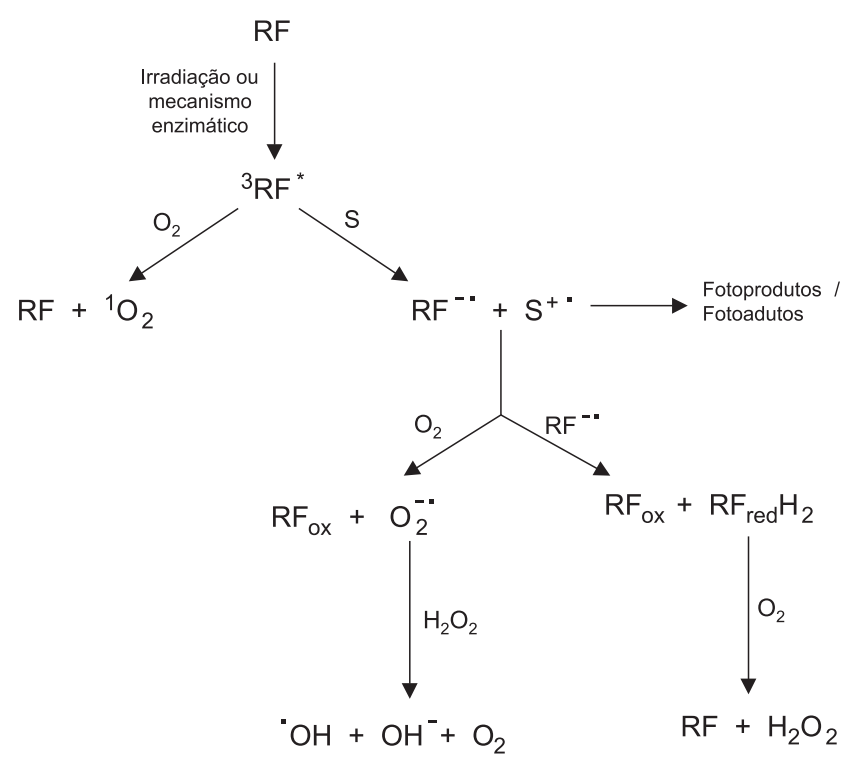

Esquema 5. Misto de mecanismos tipo I e tipo II em presença de oxigênio molecular ( $S$ representa um composto alvo da riboflavina irradiada)

Os efeitos da riboflavina irradiada em presença de $\operatorname{TrpH}$ também são observados em culturas de células não irradiadas, as quais não sofrem os efeitos deletérios das espécies reativas de oxigênio transientes formadas durante a irradiação do meio. Tais efeitos são atribuídos aos demais fotoprodutos gerados, cujas citotoxicidades são ainda mais evidentes em experimentos realizados em atmosfera anaeróbica, em que predomina o mecanismo de reação tipo $\mathrm{I}^{22,38}$. Fotoprodutos derivados do ácido 3-indolacético irradiado em presença de riboflavina demonstraram causar severos danos em cultura de células humanas HL60 e células tumorais murinas NOS $/ 2^{37}$. Tais efeitos foram mais acentuados que os anteriormente descritos para os fotoprodutos do triptofano, além de aumentarem de acordo com a elevação da concentração dos fotoprodutos ${ }^{22}$. Com base em estudos de microscopia eletrônica e análises de citometria de fluxo, demonstrou-se que tais fotoprodutos induzem morte celular por mecanismo apoptótico. Postula-se que o mecanismo de ativação apoptótica esteja relacionado à atuação dos fotoprodutos $\mathrm{I}_{3} \mathrm{~A}$ RF como ligantes sinalizadores de morte, agindo na superfície celular. Tal afirmação baseia-se no fato de que uma certa quantidade de riboflavina adicionada ao meio é incorporada pela célula, comportamento que, analogamente, também pode ser atribuído aos fotoprodutos.

Outro aspecto importante na atuação da riboflavina é sua capacidade de gerar efeitos citotóxicos mesmo quando não exposta à irradiação. $\mathrm{O}$ estado excitado de flavina triplete também pode ser alcançado em ausência de luz por um mecanismo enzimático mediado por peroxidases ${ }^{39}$, o que explica a ocorrência de efeitos citotóxicos promovidos pela riboflavina não irradada ${ }^{22}$.

Atualmente, a riboflavina e outras substâncias com capacidade fotossensibilizadora têm sido alvos de estudos na área de tratamentos e prevenção de doenças com emprego de luz. Na área oncológica, destaca-se o estudo da chamada Terapia Fotodinâmica, uma forma de fotoquimioterapia onde uma substância fotossensibilizadora é acumulada em um tecido tumoral especificamente ilu- 
minado e, subseqüentemente, destruído ${ }^{22}$. Além disso, trabalhos recentes têm demonstrado, tanto in vitro quanto in vivo, a iniciação de apoptose induzida por Terapia Fotodinâmica ${ }^{40-42}$.

\section{AGRADECIMENTOS}

À FAPESP pela Bolsa de Doutoramento à A. C. S. de Souza (Proc. no. 2002/12539-7), e de Pós-Doutoramento no Exterior à C. V. Ferreira (Proc. no. 2002/03842-8).

Os autores são gratos também ao Prof. Dr. J. de A. Simoni, do Instituto de Química da UNICAMP, pelas orientações durante a revisão final.

\section{REFERÊNCIAS}

1. Massey, V.; Biochem. Soc. Trans. 2000, 28, 283.

2. Kuhn, R.; Reinemund, K.; Weygand, F.; Ber. 1934, 67, 1460.

3. Karrer, P.; Schopp, K.; Benz, F.; Helv. Chim. Acta 1935, 18, 426.

4. Powers, J. H.; Am. J. Nutr. 2003, 77, 1352.

5. Granjeiro, J. M.; Ferreira, C. V.; Jucá, M. B.; Taga, E. M.; Aoyama, H.; Biochem. Mol. Biol. Int. 1997, 41, 1201.

6. Buzalaf, M. A. R.; Taga, E. M.; Granjeiro, J. M.; Ferreira C. V.; Lourenção, V. A.; Ortega, M. M.; Poletto, D. W.; Aoyama, H.; Exp. Lung Res. 1998 , 24, 269.

7. Edwards, A. M.; Bueno, C.; Saldaño, A.; Silva, E.; Kassab, K.; Polo, L.; Jori, G.; J. Photochem. Photobiol., B 1999, 48, 36.

8. Merrill, A. H.; Lambeth, J. D.; Edmondson, D. E.; McCornick, D. B.; Annu. Rev. Nutr. 1981, 1, 281

9. Rivlin, R. S.; Shils, M. E.; Sherlock, P.; Am. J. Med. 1983, 75, 843.

10. Souza, A. C. S., comunicação pessoal.

11. World Health Organization; WHO handbook on human nutritional requirements, 1974, Monograph series 61, Geneva.

12. EC Scientific Committee for Food Report; Nutrient and energy intakes for the European Community, Luxembourg, Directorate-General, Industry, 1993, $31^{\text {st }}$ series.

13. McCornick, D. B.; Innis, W. S. A.; Merrill, A. H. Jr; Browers-Komro, D M.; Oka, M.; Chastain, J. L. Em Flavin and Flavoproteins; Edmondson, D. E.; McCornick, D. B., eds; Walter de Gruyter: New York, 1988, p. 459-471.

14. Decker, K.; Dotis, B.; Glatzle, D.; Hinselmann, M.; Nutr. Metab. 1977, 21 17
15. Buzina, R.; Jusic, M.; Milanovic, N.; Sapurnar, J.; Brubacher, G.; Int. J. Vitam. Nutr. Res. 1979, 49, 136.

16. Powers, H. J.; Bates, C. J.; Prentice, A. M.; Lamb, W. H.; Jepson, M.; Bowman, H.; Hum. Nutr. Clin. Nutr. 1983, 37C, 413.

17. Mancini, M.; Edwards, A. M.; Becker, M. I.; De Ioannes, A.; Silva, E.; J. Photochem. Photobiol., B 2000, 55, 9.

18. Takami, Y.; Gong, H. Q.; Amemiya, T.; Ophthalmic Res. 2004, 36, 156.

19. Rivlin, R. S.; Cancer Res. 1973, 33, 1977.

20. Edwards, A. M.; Silva, E.; J. Photochem. Photobiol., B 2001, 63, 126.

21. Holladay, S. R.; Yang, Z.; Kennedy, M. D.; Leamon, C. P.; Lee, R. J.; Jayamani, L. M.; Mason, T.; Low, P. S.; Biochim. Biophys. Acta 1999, 1426, 195.

22. Edwards, A. M.; Silva, E.; Jofré, B.; Becker, M. I.; De Ioannes, A. E.; J. Photochem. Photobiol., B 1994, 24, 179.

23. Silva, E.; Fürst, S.; Edwards, A. M.; Becker, M. I.; De Ioannes, A. E.; Photochem. Photobiol. 1995, 62, 1041

24. Agarwal, M. L.; Clay, M. E.; Harvey, E. J.; Evans, H. H.; Antúnez, A. R.; Oleinick, N. L.; Cancer. Res. 1991, 51, 5993.

25. Wyllie, A. H.; Kerr, J. F. R.; Curie, A. R.; Int. Rev. Cytol. 1980, 68, 251

26. La Rochette, A.; Silva, E.; Birlouez-Aragon, I.; Mancini, M.; Edwards, A. M.; Morlière, P.; Photochem. Photobiol. 2000, 76, 815.

27. Ahmad, I.; Fasihullah, Q.; Vaid, F. H. M.; J. Photochem. Photobiol., B 2004, 75, 13

28. Silva, E.; Ugarte, R.; Andrarde, A.; Edwards, A. M.; J. Photochem. Photobiol., B 1994, 23, 43.

29. Sancar, G. B.; Mutat. Res. 2000, 451, 25.

30. Meisel, D.; Neta, P.; J. Phys. Chem. 1975, 79, 2459.

31. Joshi, P. C.; Toxicol. Lett. 1985, 26, 211.

32. Suzuki, Y.; Miura, T.; Ogiso, T.; Pharmacobiodynamics 1982, 5, 568

33. Harriman, A.; J. Phys. Chem. 1987, 91, 6102

34. Yoshimura, A.; Ohno, T.; Photochem. Photobiol. 1988, 48, 561.

35. Silva, E.; J. Photochem. Photobiol., B 1992, 14, 142.

36. Vileisis, R. A.; Sorensen, K.; González-Crussi, F.; Hunt, C. E.; J. Pediatr. 1982, 100, 88

37. Nixon, B. T.; Wang, R. J.; Photochem. Photobiol. 1977, 26, 589.

38. Edwards, A. M.; Barredo, F.; Silva, E.; De Ioannes, A. E.; Becker, M. I.; Photochem. Photobiol., 1999, 70, 645.

39. Rojas, J.; Silva, E.; Photochem. Photobiol. 1988, 47, 467.

40. Zaidi, S. I. A.; Oleinick, N. L.; Photochem. Photobiol. 1993, 58, 771

41. Luo, Y.; Chang, C. K.; Kessel, D.; Photochem. Photobiol. 1996, 63, 528.

42. He, X. Y.; Sikes, R. A.; Thomsen, S.; Chun, L. W. K.; Jacques, S. L.; Photochem. Photobiol. 1994, 59, 468. 